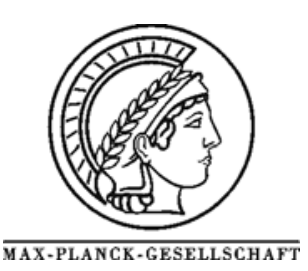

\title{
Characterization of the Synthesis and Reactivity Behavior of Nanostructured Vanadia Model Catalysts using XPS and Vibrational Spectroscopy
}

\author{
C. Hess \\ Department of Inorganic Chemistry, Fritz-Haber-Institute of the MPG, Faradayweg 4-6, 14195 Berlin, Germany \\ *Corresponding author: e-mail hess@fhi-berlin.mpg.de,
}

Available online 17 April 2006

\begin{abstract}
Nanostructured vanadia model catalysts, i.e. highly dispersed vanadium oxide supported on mesoporous silica SBA-15 (VO S SBA-15), were prepared. The mechanism for the synthesis of $\mathrm{VO}_{\mathrm{x}} / \mathrm{SBA}-15$ was elucidated by detailed characterization of the individual synthesis steps using XPS and vibrational spectrocopy. The resulting surface vanadium oxide species $\left(0-2.3 \mathrm{~V} / \mathrm{nm}^{2}\right)$, grafted on the inner pores of the SBA-15 silica matrix, consists of tetrahedrally coordinated vanadia as inferred from UV-VIS- and Raman spectroscopy. The prepared vanadia model catalysts were tested in the partial oxidation of methanol to formaldehyde yielding high formaldehyde selectivities of $94 \%$ at $350^{\circ} \mathrm{C}$. XPS and Raman analysis of the catalyst after reaction reveal the presence of methoxy as well as a significant amount of carbonaceous species on the surface. Our results demonstrate that a detailed understanding of partial oxidation reactions requires the combination of complementary spectroscopic techniques ultimately within one experimental set-up.
\end{abstract}

Keywords: supported vanadium oxide, vanadia, SBA-15, methanol oxidation, spectroscopy, XPS, Raman

\section{Introduction}

Mesoporous SBA-15 silica is a promising new support material for catalysts. First, its large internal surface area $\left(>800 \mathrm{~m}^{2} / \mathrm{g}\right)$ and $\mathrm{OH}$ concentration allow for the dispersion of a large number of catalytically active sites. Secondly, it possesses uniform hexagonal channels, which can be tuned from 5 to $30 \mathrm{~nm}$, and a very narrow pore size distribution [1]. Therefore, SBA-15 allows for rigorous control of the surface geometry at the mesoscale, which is an important ingredient for the design of catalysts [2]. Its large pores permit access to bulky reagents. Furthermore, the thick framework walls $(3.1-6.4 \mathrm{~nm})$ of SBA-15 provide high hydrothermal stability that exceeds those of other mesoporous materials e.g. thinner-walled MCM-41 [3]. Although of great potential use for catalytic applications, there have been only few reports on the preparation of SBA-15 supported catalysts by impregnation methods [4,5]. However, controlled synthesis of catalytic materials with uniform active sites is still a challenge. Previously, we have shown that highly dispersed vanadia supported on SBA-15 $\left(\mathrm{VO}_{\mathrm{x}} / \mathrm{SBA}-15\right)$ can be prepared by a novel grafting/anion exchange method, which consists of organofunc- tionalization of SBA-15, subsequent anion exchange of decavanadate into the pores of the silica matrix and thermolysis of the precursor material. As the precursor is tightly held electrostatically within the channels in a prearranged geometry, this approach allows to precisely control the amount of vanadium introduced into the material over a broad range of vanadia loadings $(0-22 \mathrm{wt} \% \mathrm{~V})$ [6]. Hence, due to its well-defined preparation and structure, this vanadia catalyst seems very well suited as a three-dimensional model system to give new insights into the nature of the active site as well as the relation between structure and activity in partial oxidation reactions.

Supported vanadia catalysts possess unique properties for a number of reactions such as the oxidation of sulfur dioxide to sulfur trioxide [7], oxidation of o-xylene to phthalic anhydride $[8,9]$ and selective catalytic reduction of $\mathrm{NO}_{\mathrm{x}}[7,10]$. The gas-phase partial oxidation of methanol to formaldehyde is an important probe reaction, as its product selectivity depends on the surface concentration of redox, basic and acidic sites [7,9,11,12,13]. Redox sites produce formaldehyde, methyl formate and dimethoxy methane, whereas acidic and basic sites give rise to dimethyl ether and carbon oxides $\left(\mathrm{CO}_{\mathrm{x}}\right)$, respectively. Silica-supported 
vanadia catalysts are very selective towards formaldehyde, but exhibit a rather low activity in comparison to a series of vanadia catalysts supported on other oxides, such as titania $[9,12]$. Only recently, the reactivity behavior of SBA-15 supported vanadia was studied for the photo-induced oxidation of methane to formaldehyde [4] and oxidative dehydrogenation $(\mathrm{ODH})$ of propane [5].

In this contribution, reactivity and spectroscopic results for the partial oxidation of methanol to formaldehyde over SBA-15 supported vanadium oxide are presented. Raman and XPS characterization of the catalyst after reaction is used to monitor adsorbed species as well as structural changes of the surface vanadium oxide species during methanol oxidation. We focus on well-characterized vanadia catalysts with a high dispersion of uniform active vanadia sites $\left(0-2.3 \mathrm{~V} / \mathrm{nm}^{2}\right)$.

\section{Experimental}

\subsection{Catalyst Preparation}

Silica SBA-15 was synthesized according to the literature [1]. Functionalization of SBA-15 was achieved by stirring $2.5 \mathrm{~g}$ SBA- 15 in $100 \mathrm{ml}$ of toluene at $65^{\circ} \mathrm{C}$ [14]. To this suspension, $6.5 \mathrm{~g}$ 3-aminopropyltrimethoxysilane (APTMS) was added while stirring. After stirring for 12 hours, the contents were filtered, washed with toluene and stirred in $150 \mathrm{ml} 0.3 \mathrm{M} \mathrm{HCl}$ for 12 hours. The contents were filtered again, washed with water and dried in air overnight. SBA-15 supported vanadia was synthesized using functionalized SBA-15 and butylammonium decavanadate as starting material, which was synthesized according to a previous report [15]. For $\mathrm{VO}_{\mathrm{x}} / \mathrm{SBA}-15$ catalysts, appropriate amounts of butylammonium decavanadate were added to a suspension of functionalized SBA-15 in water [6]. The contents were stirred for 12 hours, filtered, washed with water and dried in air. The powder was calcined at $550^{\circ} \mathrm{C}$ for 12 hours.

\subsection{Physical Characterization}

The vanadium content of the $\mathrm{VO}_{\mathrm{x}} / \mathrm{SBA}-15$ samples was determined by atomic absorption spectroscopy (AAS) and by inductively coupled plasma atomic emission spectroscopy (ICP). Surface areas of the prepared samples were measured by nitrogen adsorption/desorption isotherms and standard multipoint BET analysis methods. The pore volume was determined from the adsorption branch of the $\mathrm{N}_{2}$ isotherm curve at the $\mathrm{P} / \mathrm{P}_{0}=0.995$ signal point. The poresize distribution was calculated using the Barrett-JoynerHalenda (BET) method. Elemental analysis reveals $\mathrm{Cu}, \mathrm{Ni}$ and $\mathrm{Zn}$ in the ppm level of the prepared SBA- 15 .

\subsection{Raman Spectroscopy}

Raman spectra were measured using $532 \mathrm{~nm}$ $(25 \mathrm{~mW})$ or $514 \mathrm{~nm}(10 \mathrm{~mW})$ excitation at $5 \mathrm{~cm}^{-1}$ spectral resolution (Kaiser Optical). For catalyst characterization, the samples were pressed into pellets and rotated at $20 \mathrm{~Hz}$ within a quartz in situ Raman cell. Raman spectra under dehydrated conditions were recorded at room temperature after treating the samples in flowing air at $400^{\circ} \mathrm{C}$ for $1 \mathrm{~h}$. Raman analysis before and after reaction was performed by using a fiber probe. The powder samples were placed as is in a stainless steel holder (see below). Sampling times were typically $5 \mathrm{~min}$.

\subsection{UV-VIS Diffuse Reflectance Spectroscopy}

Diffuse reflectance UV-VIS spectra were measured with a Varian-Cary 4 spectrometer equipped with a Harrick diffuse reflectance attachment. Samples were dehydrated in $20 \% \mathrm{O}_{2} / \mathrm{He}$ at $300^{\circ} \mathrm{C}$ for $1 \mathrm{~h}$ before measuring spectra between $1 \mathrm{eV}$ and $5 \mathrm{eV}$ at ambient temperature. The KubelkaMunk function $\left(\mathrm{F}\left(\mathrm{R}_{\infty}\right)\right)$ was used to convert diffuse reflectance data into absorption spectra using $\mathrm{MgO}$ as a standard.

\subsection{X-ray photoelectron spectroscopy}

The measurements were carried out using a modified LHS/SPECS EA200 MCD system equipped with a $\mathrm{Mg} \mathrm{\textrm {K } _ { \alpha }}$ source $(1253.6 \mathrm{eV}, 168 \mathrm{~W})$. The binding energy scale of the system was calibrated using $\mathrm{Au} 4 \mathrm{f}_{7 / 2}=84.0 \mathrm{eV}$ and $\mathrm{Cu}$ $2 p_{3 / 2}=932.67 \mathrm{eV}$ from foil samples. The powder samples were placed as is in a stainless steel sample holder with a $0.6 \mathrm{~mm}$ deep rectangular well covering an area of $(12 \times 8) \mathrm{mm}^{2}$. The base pressure of the ultra-high vacuum (UHV) chamber was $1 \times 10^{-10}$ mbar. Charging of the powder samples was accounted for by setting the peak of the Si $2 p$ signal to $103.6 \mathrm{eV}$ [16]. A Shirley background was subtracted from all spectra. Then peak fitting with a 30/70 Gauss-Lorentz product function was performed. For the reaction experiments, the sample holder was introduced into a reaction cell attached to the XPS set-up. The $\mathrm{MeOH} / \mathrm{O}_{2} / \mathrm{He}$ gas mixture $(4 / 4 / 32)$ was introduced to the reactor at a total flow rate of $40 \mathrm{ml} / \mathrm{min}$.

\subsection{Reactivity Experiments}

$200 \mathrm{mg}$ of catalyst was loaded into a tubular flow reactor (i.d.10 mm) placed in a tubular furnace. Each catalyst was pretreated at $500^{\circ} \mathrm{C}$ for $1 \mathrm{~h}$ in a stream of synthetic air $\left(20 \% \mathrm{O}_{2}, 80 \% \mathrm{He}\right)$ prior to each run. Following pretreatment, a $\mathrm{MeOH} / \mathrm{O}_{2} / \mathrm{He}$ gas mixture (3/7/90) was introduced to the reactor at a total flow rate of $100 \mathrm{ml} / \mathrm{min}$. The reactant and product mix was analyzed by gas chromatography. 
Table 1: BET characteristics of the synthesized SBA-15 supported vanadium oxides compared to the blank SBA-15 support.

\begin{tabular}{lcccccc}
\hline & $\begin{array}{c}\mathrm{V} \\
(\mathrm{wt} \%)\end{array}$ & $\mathrm{V} / \mathrm{nm}^{2}$ & $\begin{array}{c}\mathrm{V} \\
(\mathrm{mmol} / \mathrm{g})\end{array}$ & $\begin{array}{c}\mathrm{S}_{\mathrm{BET}} \\
\left(\mathrm{m}^{2} / \mathrm{g}\right)\end{array}$ & $\begin{array}{c}\mathrm{r}_{\mathrm{p}} \\
(\mathrm{nm})\end{array}$ & $\begin{array}{c}\mathrm{V}_{\mathrm{p}} \\
(\mathrm{mL} / \mathrm{g})\end{array}$ \\
\hline SBA-15 & 0.0 & 0.0 & 0.0 & 826 & 3.58 & 0.77 \\
$\mathrm{VO}_{\mathrm{x}} /$ SBA-15 & 2.7 & 0.7 & 0.53 & 445 & 3.26 & 0.46 \\
& 7.2 & 2.3 & 1.4 & 369 & 2.83 & 0.36 \\
\hline
\end{tabular}

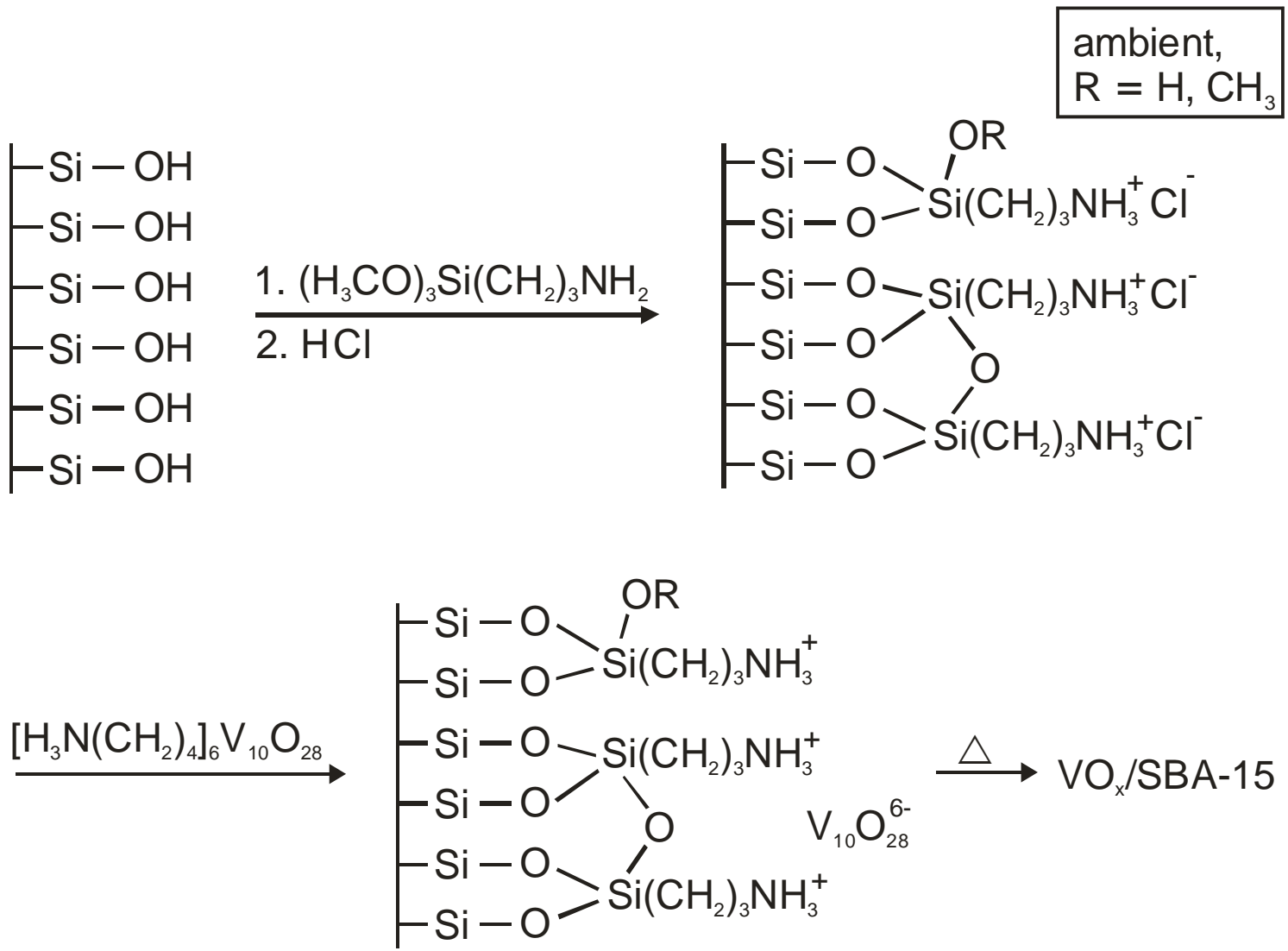

Figure 1: Reaction mechanism for the formation of $\mathrm{VO}_{\mathrm{x}} / \mathrm{SBA}$.

The reported conversion values were calculated based on an appropriate weighted sum of the product concentrations (eqn. 1)

$$
\mathrm{MeOH} \text { Conversion }=\left(\sum_{i} v_{i} X_{i}\right) * 100
$$

where $v_{\mathrm{i}}$ is the number of carbons from methanol necessary to make product $i$, and $X_{i}$ is the mole fraction of product $i$. The selectivity (\%) of product $i$ is reported on the basis of product areas as (the number of moles of methanol converted to product $i) /($ total number of moles of methanol converted) $\times 100$. The turnover frequency, TOF $\left(\mathrm{s}^{-1}\right)$ is the number of moles of methanol converted to formaldehyde per mole of surface vanadium atom per second.

\section{Results and Discussion}

\subsection{Synthesis of $V O_{x} / S B A-15$.}

The synthesis and characterization of SBA-15 has been discussed previously [1]. The results of the $\mathrm{N}_{2}$ physisorption analysis of SBA-15 and the $\mathrm{VO}_{\mathrm{x}} / \mathrm{SBA}-15(0$ $7.2 \mathrm{wt} \% \mathrm{~V}$ ) samples are given in Table 1. With increasing vanadia loading, the surface areas, pore radii and pore volumes of the $\mathrm{VO}_{\mathrm{x}} / \mathrm{SBA}-15$ shift to lower values (see Table 1). However, physisorption data also reveals that in the presence of surface vanadia, the mesoporous channels remain accessible. The pore radius and pore volume decrease significantly with loading, which suggests that the vanadia species are located inside the pores of SBA-15, coating the inner walls of the mesoporous matrix. 

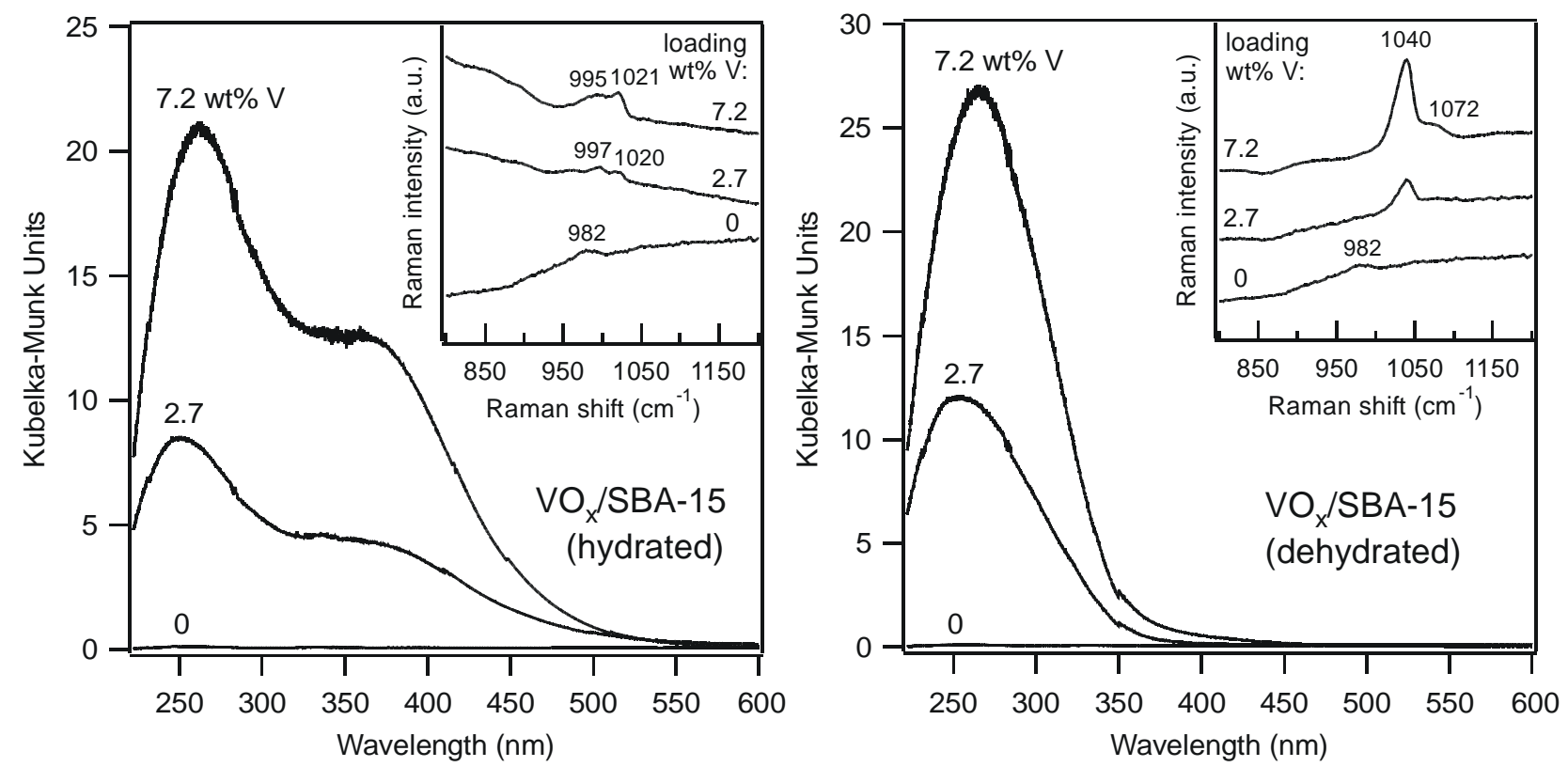

Figure 2: UV-VIS diffuse reflectance spectra of hydrated (left) and dehydrated (right) SBA-15 supported vanadium oxide catalysts. The insets show the corresponding Raman spectra.

\subsection{Reaction Mechanism for the Formation of VO $O_{x} / S B A-15$}

On the basis of the results obtained from Raman and $\mathrm{XP}$ spectroscopy, the reaction mechanism shown in Fig. 1 has been proposed [6]: (1) The surface of SBA-15 is modified via its hydroxyl groups by grafting of APTMS and subsequent treatment with $\mathrm{HCl}$. Under ambient conditions, the protonated APTMS is present in its bidentate and tridentate forms as shown in Fig. 1 [17]. (2) During the anion exchange reaction, decavanadate $\left(\mathrm{V}_{10} \mathrm{O}_{28}{ }^{6-}\right)$ is incorporated intactly into the pores of the silica matrix without structural changes of the organic framework. (3) Thermal decomposition of the decavanadate precursor material yields the final supported vanadia catalyst $\left(\mathrm{VO}_{\mathrm{x}} / \mathrm{SBA}-15\right)$. During this process, all organic residues as well as chlorine and sodium are completely removed from the pores.

\subsection{Spectroscopic Characterization of $V O_{x} / S B A-$ 15}

UV-VIS spectra of the blank SBA-15 support and the $\mathrm{VO}_{\mathrm{x}} / \mathrm{SBA}-15$ samples are depicted in Fig. 2 in their hydrated (left panel) and dehydrated (right panel) state. The corresponding Raman spectra are shown as insets. The dehydrated $\mathrm{VO}_{\mathrm{x}} / \mathrm{SBA}-15$ samples give rise to absorption bands at 250 and $292 \mathrm{~nm}$, respectively. The position of their maxima agrees well with that of orthovanadate reference compounds such as $\mathrm{Na}_{3} \mathrm{VO}_{4}$ [18] and $\mathrm{Mg}_{3} \mathrm{~V}_{2} \mathrm{O}_{8}$ $[19,20]$. Also, the corresponding Raman spectra are dominated by a band at $1040 \mathrm{~cm}^{-1}$ (see inset), which has been assigned to isolated tetrahedral $\mathrm{VO}_{4}$ with three $\mathrm{V}-\mathrm{O}_{\text {support }}$ bonds and one $\mathrm{V}=\mathrm{O}$ bond in the literature [21-25]. It should be mentioned, that recent studies have challenged the above assignment [26,27]. At a loading of $7.2 \mathrm{wt} \% \mathrm{~V}$, an additional band appears at $362 \mathrm{~nm}$ [28]. The position of this band indicates the presence of polymerized $\mathrm{VO}_{4}$, but its contribution to the total intensity is small [6].

Besides the Raman band at $1040 \mathrm{~cm}^{-1}$, the dehydrated vanadia samples give rise to additional bands at $915 \mathrm{~cm}^{-1}$ and $1072 \mathrm{~cm}^{-1}$, which can be assigned to Si-Oand $\mathrm{Si}\left(-\mathrm{O}^{-}\right)_{2}$ functionalities indicating the formation of $\mathrm{V}$ O-Si $[29,23]$. In contrast to the vanadia samples, the blank SBA-15 support gives rise to only one Raman band at $987 \mathrm{~cm}^{-1}$, which is characteristic of the $\mathrm{Si}-\mathrm{OH}$ stretching mode of surface hydroxyls [30]. Obviously, upon grafting of vanadia, its intensity decreases as a result of the reaction of $\mathrm{Si}-\mathrm{OH}$ with the vanadia precursor.

Hydrated $\mathrm{VO}_{\mathrm{x}} / \mathrm{SBA}-15$ samples show an additional UV-VIS strong absorption band at $\sim 370 \mathrm{~nm}$, while the band at $\sim 260 \mathrm{~nm}$ is reduced in intensity compared to the dehydrated samples. This indicates that part of the tetrahedral species has been transformed into pentagonal or pseudooctahedral $\mathrm{V}^{5+}$ ions by coordination to water molecules and subsequent polymerization. These structural changes are confirmed by the Raman spectra (see inset) which give rise to bands characteristic of hydrated $\mathrm{VO}_{\mathrm{x}} / \mathrm{SBA}-15$. Previously, similar bands have been observed on amorphous silica and were assigned to a $\mathrm{V}_{2} \mathrm{O}_{5} \cdot n \mathrm{H}_{2} \mathrm{O}$ gel $[22,23]$. The slightly different Raman frequencies and relative peak intensities of the two vanadia samples are attributed to a different degree of hydration. 
Table 2: Reactivity data for methanol oxidation to formaldehyde over $\mathrm{VO}_{\mathrm{x}} / \mathrm{SBA}-15$ catalysts as well as SBA-15 at $350^{\circ} \mathrm{C}$

\begin{tabular}{|c|c|c|c|c|c|c|c|}
\hline $350^{\circ} \mathrm{C}$ & Conversion (\%) & $\begin{array}{c}\mathrm{TOF}^{\mathrm{a}} \\
\left(\mathrm{x} 10^{3} \mathrm{~s}^{-1}\right) \\
\end{array}$ & FA & $\mathrm{MF}$ & $\begin{array}{c}\text { Selectivity } \\
\text { DMM }\end{array}$ & DME & $\mathrm{CO}_{\mathrm{x}}$ \\
\hline SBA-15 & 27 & & 29.7 & 1.7 & 0.1 & 0.0 & 68.5 \\
\hline $2.7 \mathrm{wt} \% \mathrm{~V} / \mathrm{SBA}-15$ & 15.7 & 3.7 & 94 & 0.3 & 0 & 0.1 & 5.6 \\
\hline $7.2 \mathrm{wt} \% \mathrm{~V} / \mathrm{SBA}-15$ & 39 & 2.6 & 93.3 & 0.4 & 0.1 & 0.9 & 5.3 \\
\hline
\end{tabular}

${ }^{\mathrm{a}}$ Apparent TOF values
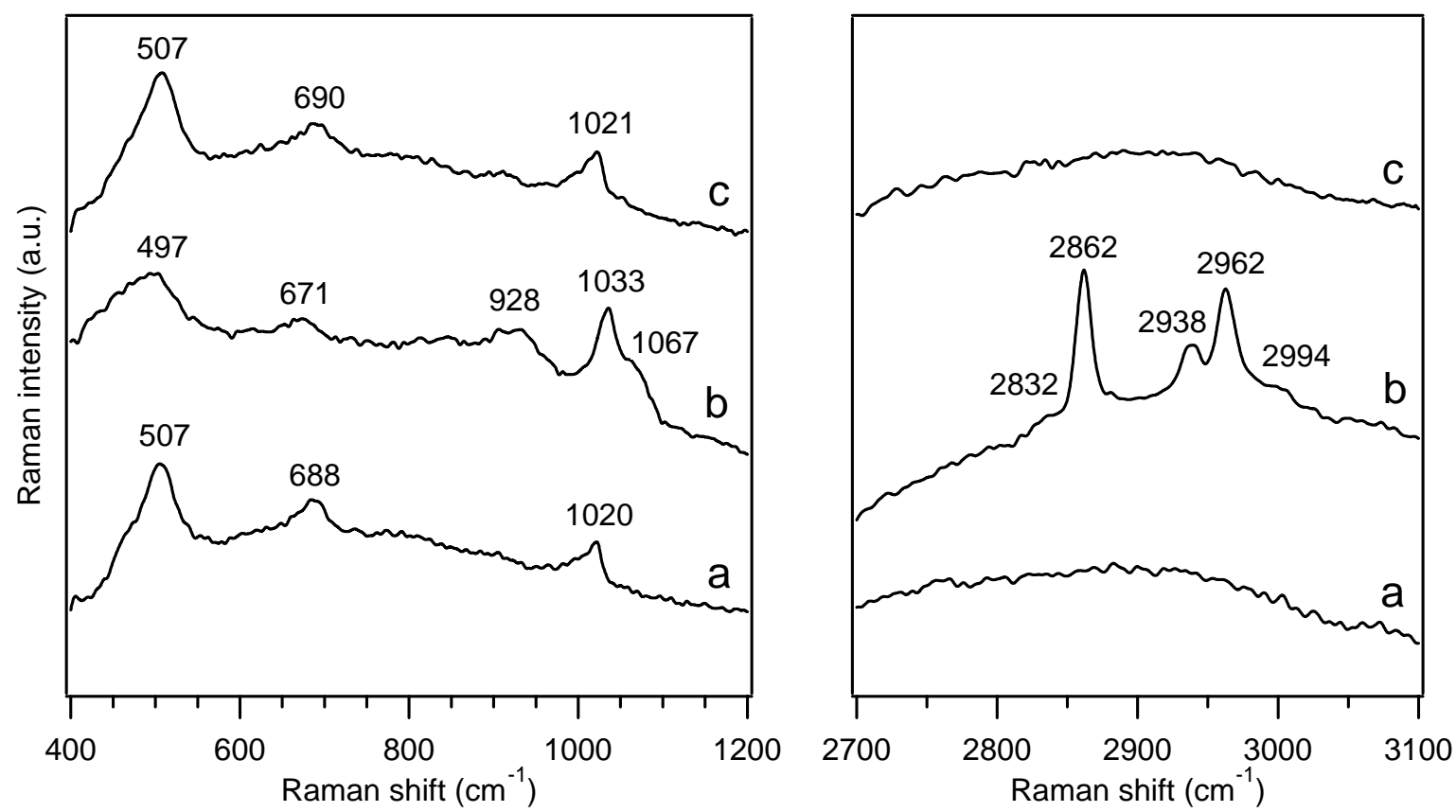

Figure 3: Raman spectra of $2.7 \mathrm{wt} \% \mathrm{~V} / \mathrm{SBA}-15$ (a) before methanol oxidation (b) after methanol oxidation at $350^{\circ} \mathrm{C}$ for 1 hour and (c) after subsequent treatment in $\mathrm{O}_{2} / \mathrm{N}_{2}$ at $350^{\circ} \mathrm{C}$ for $1 \mathrm{~h}$. All spectra were taken under ambient conditions and at room temperature. They are offset for clarity.

\subsection{Reactivity Behavior during Methanol Oxida- tion}

Table 2 shows the reactivity data for the partial oxidation of methanol to formaldehyde over highly dispersed vanadia supported on SBA-15 at $350^{\circ} \mathrm{C}$. Negligible gas phase activity was found. The results in Table 2 clearly show that SBA-15 supported vanadium oxides are very selective towards formaldehyde. For example, for a $2.7 \mathrm{wt} \% \mathrm{~V} / \mathrm{SBA}-15$ catalyst, a selectivity of $94 \%$ was obtained $\left(350^{\circ} \mathrm{C}, 15 \%\right.$ methanol conversion). The TOF shows no variation with increasing vanadium loading within the experimental error. This result may be expected from the spectroscopic data given in Fig. 2, which show only minor structural changes of the surface vanadia species with increasing loading [12]. Besides formaldehyde (FA), small amounts of methyl formate (MF), dimethoxymethane (DMM) and dimethyl ether (DME) as well as $\mathrm{CO}_{\mathrm{x}}$ are formed over $\mathrm{VO}_{\mathrm{x}} / \mathrm{SBA}-15$. MF and $\mathrm{DMM}$ are produced over redox sites (as is FA), while DME and $\mathrm{CO}_{\mathrm{x}}$ form over acidic and basic sites, respectively. The oxidation of methanol yields DME indicating the presence of acidic sites. Interestingly, no DME is observed for the blank SBA-
15 support. This behavior is in agreement with the results from recent $\mathrm{NH}_{3}$ TPD studies on SBA-15 [5], which have shown no appreciable desorption peaks corresponding to medium acid sites. The formation of significant amounts of FA and MF indicates the presence of redox sites on the bare support. Although transition metal contamination found in the SBA-15 may explain this activity (see above), the intrinsic activity of SBA-15 is supported by reactivity experiments on ultrapure SBA-15, which show a significantly higher activity compared to conventional SBA-15 [31]. In comparison, for $\mathrm{MCM}$ and conventional $\mathrm{SiO}_{2}$ materials, the formation of DME but no methyl formate was observed [32]. These results indicate significant differences in the properties of conventionally prepared SBA-15 compared to other $\mathrm{SiO}_{2}$ materials, which are currently under study in our laboratory. 

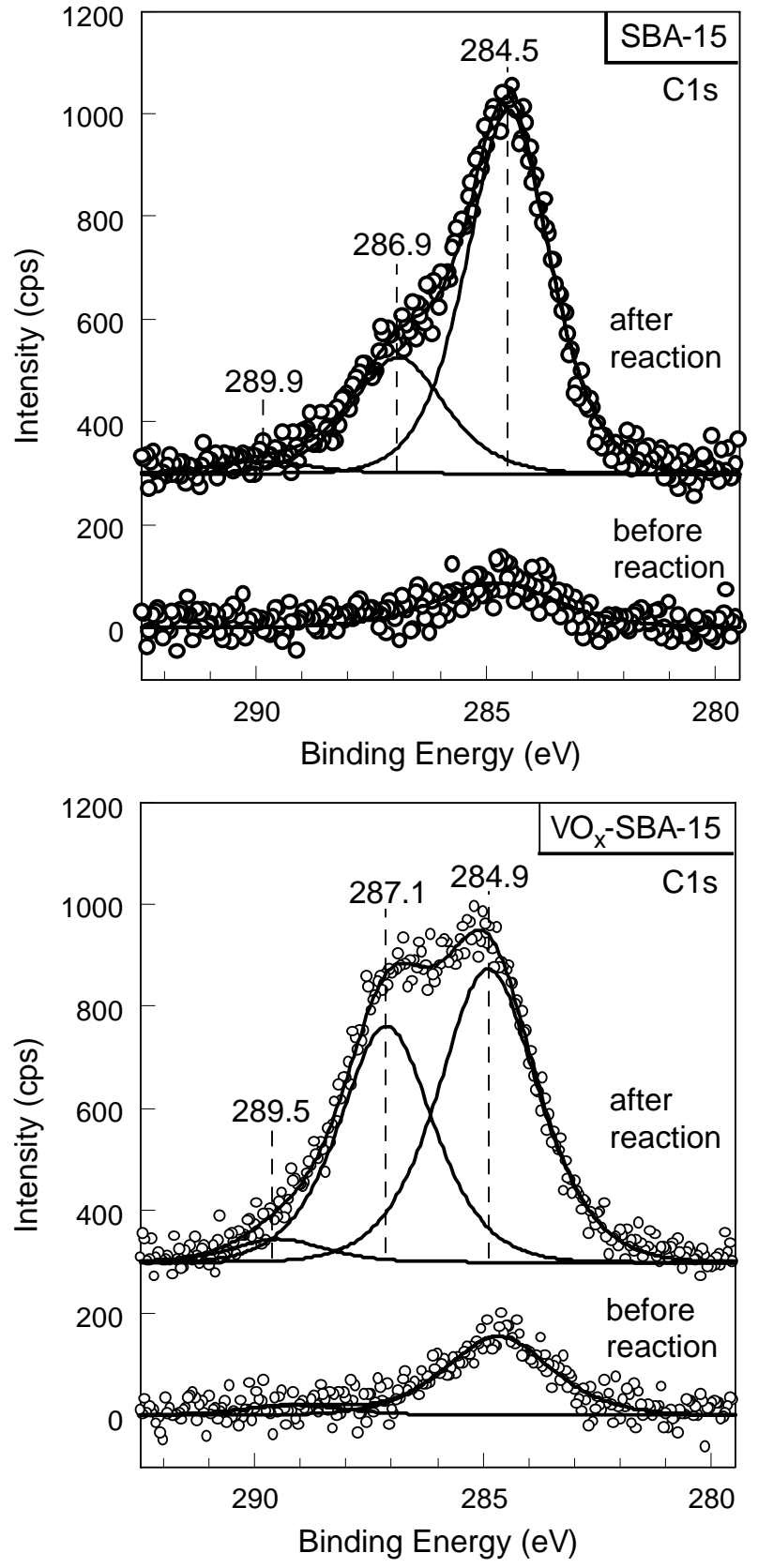

Figure 4: XP C 1s spectra of bare SBA-15 (above) and $2.7 \mathrm{wt} \% \mathrm{~V} / \mathrm{SBA}-15$ together with the results from the peak fitting procedure (a) before methanol oxidation (b) after methanol oxidation at $350^{\circ} \mathrm{C}$ for 1 hour.

\subsection{Catalyst Characterization after Methanol Oxidation}

Figure 3 shows Raman spectra of a $2.7 \mathrm{wt} \%$ V/SBA15 catalyst taken at room temperature before (a) and after (b) exposure to the $\mathrm{MeOH} / \mathrm{O}_{2} / \mathrm{N}_{2}$ gas mixture for 1 hour at $350^{\circ} \mathrm{C}$, at which reaction occurs. After treatment in $\mathrm{O}_{2} / \mathrm{N}_{2}$ $(20 / 12)$ at $350^{\circ} \mathrm{C}$ for 1 hour at a total flow rate of $32 \mathrm{ml} / \mathrm{min}$, spectrum c was obtained. Spectrum a is characterized by bands at 507,688 , and $1020 \mathrm{~cm}^{-1}$, which can be assigned to hydrated vanadium oxide forming a $\mathrm{V}_{2} \mathrm{O}_{5} \bullet n \mathrm{H}_{2} \mathrm{O}$ gel-like structure [22,23]. Exposure to the
$\mathrm{MeOH} / \mathrm{O}_{2} / \mathrm{N}_{2}$ gas mixture under reaction conditions leads to dramatic changes in the Raman spectrum (b). Bands appear at 497, 671, 928, 1033, 1067, 2832, 2862, 2938, 2962 and $2994 \mathrm{~cm}^{-1}$. The bands in the high-frequency region result from adsorbed methanol forming a methoxy species. They can be attributed to $\mathrm{C}-\mathrm{H}$ symmetric stretching vibrations of methoxy adsorbed on silica SBA-15 $\left(2862,2962,2994 \mathrm{~cm}^{-1}\right)$ and vanadia $\left(2832,2938 \mathrm{~cm}^{-1}\right)$ as shown previously for vanadia supported on Cab-O-Sil [33]. The Raman band at $1033 \mathrm{~cm}^{-1}$ is assigned to the stretching vibration of $\mathrm{V}=\mathrm{O}$ double bonds in hydrated vanadium oxide forming a $\mathrm{V}_{2} \mathrm{O}_{5} \cdot n \mathrm{H}_{2} \mathrm{O}$ gel-like structure. The blue-shift of the band at $1023 \mathrm{~cm}^{-1}$ can be explained by the variation of the water content $\mathrm{n}$ in the gel [23]. In the same study it has been shown, that the variation of the water content in the gel can also lead to the presence of an additional band at $\sim 915 \mathrm{~cm}^{-1}$, which has been attributed to the stretching of $\mathrm{V}=\mathrm{O}$ double bond coordinated with water. Also, in an earlier study, the appearance of a Raman band at $\sim 920 \mathrm{~cm}^{-1}$ upon exposure to water had been reported [22]. On the basis of these results, the broad band around $928 \mathrm{~cm}^{-1}$ is assigned to the stretch vibration of $\mathrm{V}=\mathrm{O}$ double bonds coordinated with water. Obviously, the presence of methanol in the gel cannot be ruled out. The band at $671 \mathrm{~cm}^{-1}$ and the shoulder at $1067 \mathrm{~cm}^{-1}$ can be associated with the V-O and C-O stretching of a V-methoxy species, respectively $[23,34]$. This assignment is supported by the fact that the shoulder as well as the other methoxy related bands disappear upon heating in oxygen (see spectrum c). After treating the catalyst in $\mathrm{O}_{2} / \mathrm{N}_{2}$ at $350^{\circ} \mathrm{C}$ for $1 \mathrm{~h}$, spectrum $\mathrm{c}$ was recorded. It shows strong similarity with spectrum a, recorded before reaction, and is characterized by Raman bands at 507, 690, and $1021 \mathrm{~cm}^{-1}$.

Complementary information on the catalyst surface after reaction can be obtained from XPS, which provides quantitative information on the amount of methoxy present after reaction as well as surface composition in general. First results are presented in the following. The right panel of Fig. 4 depicts the high-resolution $\mathrm{C} 1 \mathrm{~s}$ spectrum of a $2.7 \mathrm{wt} \% \mathrm{~V} / \mathrm{SBA}-15$ catalyst together with the results from the peak fitting procedure. The spectra were taken at room temperature before (bottom) and after (top) methanol oxidation reaction without exposure to air while transferring the sample from the reaction cell to the analysis chamber. For comparison, the corresponding $\mathrm{C} 1 \mathrm{~s}$ spectra of the bare SBA-15 support are shown in the left panel. Besides carbon and the constituents of the catalyst, V, O and $\mathrm{Si}$, no other elements were detected before and after reaction. Before reaction, the spectrum of $2.7 \mathrm{wt} \% \mathrm{~V} / \mathrm{SBA}-15$ shows only one feature at $284.7 \mathrm{eV}$. However, after reaction, the spectrum is characterized by peaks at $284.9 \mathrm{eV}(54.6 \%)$, $287.1 \mathrm{eV}(41.5 \%)$ and $289.5 \mathrm{eV}(3.9 \%)$. They are assigned to $\mathrm{C}_{\mathrm{x}} \mathrm{H}_{\mathrm{y}}$ species, carbon bound to single oxygen and carbonyl-type carbon, respectively. The presence of carbonyltype carbon indicates that part of the $\mathrm{CO}_{2}$ formed during reaction is bound to the surface. The $\mathrm{C}-\mathrm{O}$ peak at $287.1 \mathrm{eV}$ is assigned to methoxy, in good agreement with the literature [35]. Though the exact bonding nature of the $\mathrm{C}_{\mathrm{x}} \mathrm{H}_{\mathrm{y}}$ 
deposit has to be studied in more detail in the future, on the basis of the fit results, we can determine the amount of $\mathrm{C}_{\mathrm{x}} \mathrm{H}_{\mathrm{y}}$ species to be 1.3 times larger than that of methoxy. Also, based on the results for bare SBA-15 shown in the left panel of Fig. 4 - $284.5 \mathrm{eV}$ (71.6\%), $286.9 \mathrm{eV}$ (25.7\%) and $289.9 \mathrm{eV}(2.7 \%)$ - we can conclude that $74 \%$ of methoxy present on $\mathrm{VO}_{\mathrm{x}} / \mathrm{SBA}-15$ after reaction is bound to vanadium. These XPS results nicely demonstrate that after reaction methoxy is bound to both vanadium and silica in good agreement with the results from Raman spectroscopy.

\section{Conclusions and Outlook}

In summary, highly dispersed uniform vanadia supported on mesoporous silica SBA-15 was prepared, characterized and its reactivity studied for the partial oxidation of methanol to formaldehyde. The SBA-15 supported vanadium oxide species are highly selective for the production of formaldehyde yielding selectivities of $94 \%$ at $350^{\circ} \mathrm{C}$ and $16-39 \%$ methanol conversion. Our $\mathrm{VO}_{\mathrm{x}} / \mathrm{SBA}-15$ catalysts constitute a new class of vanadia model systems, which are well-defined in preparation and structure and provide full catalytic function, as shown above. Therefore, they are well suited to investigate important but barely studied phenom-

\section{References and Notes}

[1] D.Y. Zhao, J.L. Feng, Q.S. Huo, N. Melosh, G.H. Fredrickson, B.F. Chmelka, G.D. Stucky, Science 279 (1998) 548.

[2] D. Trong On, D. Desplantier-Giscard, C. Danumah, S. Kaliaguine, Appl. Cat. A 222 (2001) 299.

[3] K. Cassiers, T. Linssen, M. Matthieu, M. Benjelloun, K. Schrijnemakers, P. Van der Poort, P. Cool, E.F. Vansant, Chem. Mater. 14 (2002) 2317.

[4] H.H. Lopez, A. Martinez, Catal. Lett. 83 (2002) 37.

[5] Y.-M. Liu, Y. Cao, N. Li, W.-L. Feng, W.-L. Dai, S.-R. Yan, H.-Y. He, K.-N. Fan, J. Catal. 224 (2005) 417 and references therein.

[6] C. Hess, J.D. Hoefelmeyer, T.D. Tilley, J. Phys. Chem. B 108 (2004) 9703

[7] G. Deo, I.E. Wachs, J. Haber, Crit. Rev. Surf. Chem. 4 (1994) 141.

[8] C.R. Dias, M.F. Portela, G.C. Bond, J. Catal. 157 (1995) 344.

[9] G.C. Bond, S.F. Tahir, Appl. Catal. 71 (1991) 1.

[10] E.T.V. Vogt, A. Boot, A.J. van Dillen, J.W. Geus, F.J.J.G.

Janssen, F.M.G. van der Kerkhof, J. Catal. 114 (1988) 313.

[11] M. Baltes, P. Van der Voort, O. Collart, E.F. Vansant, J.

Porous Mater. 5 (1998) 357.

[12] G. Deo, I.E. Wachs, J. Catal. 146 (1994) 323.

[13] P. Van der Voort, M. Baltes, M.G. White, E.F. Vansant, Interf. Sci. 5 (1997) 209.

[14] W.A. Carvalho, M. Wallau, U. Schuchardt, J. Mol. Catal. A 144 (1999) 91

[15] P. Roman, A. Aranzabe, A. Luque, J.M. Gutierrez-Zorilla, Mat. Res. Bull. 26 (1991) 731.

[16] Klaasen, M.; Berndtsson, A.; Hedman, J.; Nilsson, R.; Nyholm, R., and Nordling, C. J. Electron. Spectrosc. Relat. Phenom. 3 (1974) 427; Morgan, W.E.; Van Wazer, J. R. J. Phys. Chem. 77 (1973) 96; Barr, T.L. Appl. Surf. Sci. 15 (1983) 1.

[17] This is confirmed by preliminary results from ${ }^{29} \mathrm{Si}$ CPMASNMR performed by Ulla Gro Nielson. ena such as the change in vanadia dispersion during reaction and the role of the carbonaceous deposit.

While Raman spectroscopy gives valuable information on the surface vanadia as well as adsorbate species and can be extended to yield in situ spectroscopic information, XPS allows for quantification of the surface composition after reaction. Therefore, it seems promising to combine these complementary spectroscopic techniques within one experiment to obtain a more detailed understanding of partial oxidation reactions in the near future.

\section{Acknowledgement}

It is pleasure to thank Robert Schlögl for continuous support. The author gratefully acknowledges Ian Drake for help with the reactivity experiments and Ute Wild for technical assistance with the XPS set-up. The work is supported by SFB 546 of the Deutsche Forschungsgemeinschaft (DFG). C. H. thanks the Max-Planck Society for providing an Otto Hahn fellowship and the Deutsche Forschungsgemeinschaft (DFG) for providing an Emmy Noether fellowship.

[18] M. Nabavi, F. Taulelle, C. Sanchez, M. Verdaguer, J. Phys. Chem. Solids 51 (1990) 1375.

[19] (a) D.S.H. Sam, V. Soenen, J.C. Volta, J. Catal. 123 (1990) 417. (b) G. Busca, G. Ricchiardi, D.S.H. Sam, J.C. Volta, J. Chem. Soc. Faraday Trans. 90 (1994) 1161.

[20] N. Krishnamachari, C. Calvo, Can. J. Chem. 49 (1971) 1629. [21] (a) M. Schraml-Marth, M., A. Wokaun, M. Pohl, H.L. Krauss, J. Chem. Soc. Faraday Trans. 87 (1991) 2635. (b) U. Scharf, M. Schraml-Marth, A. Wokaun, A. Baiker, J. Chem. Soc. Faraday Trans. 87 (1991) 3299.

[22] S. Xie, E. Iglesia, E., A.T. Bell, Langmuir 16 (2000) 7162.

[23] X. Gao, S.R. Bare, B. Weckhuysen, I.E. Wachs, J. Phys. Chem. B 102 (1998) 10842.

[24] N. Das, H. Eckert, H. Hu, I.E. Wachs, J.F. Walzer, F.J. Feher, J. Phys. Chem. 97 (1993) 8240.

[25] G.T. Went, S.T. Oyama, A.T. Bell, J. Phys. Chem. 94 (1990) 4240 .

[26] N. Magg, B. Immaraporn, J.B. Giorgi, T. Schroeder, M. Bäumer, J. Döbler, Z. Wu, E. Kondratenko, M. Cherian, M. Baerns, P.C. Stair, J. Sauer, H.-J. Freund, J. Catal. 226 (2004) 88. [27] O.L.J. Gijzeman, J.N.J. van Lingen, J.H. van Lenthe, S.J. Tinnemanns, D.E. Keller, B. Weckhuysen, Chem. Phys. Lett. 397 (2004) 277.

[28] The UV-VIS spectra shown in figure 1 have been deconvoluted. As a result, the spectrum of a sample with Vanadium loading of $7.2 \mathrm{wt} \%$ can be described by three bands with absorption maxima at 250, 292 and $362 \mathrm{~nm}$, respectively. A more detailed description is given elsewhere [6].

[29] P. McMillan, Am. Mineral. 69 (1986) 622.

[30] (a) D.R. Tallant, B.C. Bunker, C.J. Brinker, C.A. Balfe, Mater. Res. Soc. Symp. Proc. 73 (1986) 261. (b) R.H. Stolen, G.E. Walrafen, J. Chem. Phys. 64 (1976) 2623. (c) B.C. Brinker, D.R. Tallant, E.P. Roth, C.S. Ashley, Mater. Res. Soc. Symp. Proc. 61 (1986) 387. 
[31] Ultrapure SBA-15 was synthesized according to the literature [1], but the reagents used were $99.999 \%$ TEOS, $20 \%$ doubly distilled $\mathrm{HCl}$ and ultrapure $\mathrm{H}_{2} \mathrm{O}$.

[32] M. Baltes, K. Cassiers, P. Van der Voort, B.M. Weckhuysen, R.A. Schoonheydt, E.F. Vansant, J. Catal. 197 (2001) 160.

[33] J.-M. Jehng, H. Hu, X. Gao, I.E. Wachs, Catal. Today 28 (1996) 335.
[34] J. Döbler, M. Pritzsche, J. Sauer, J. Am. Chem. Soc. (published on web).

[35] C.G. Pantano, T.N. Wittberg, Surf. Interface Anal. 15 (1990) 498; A. M. De Asha, J.T.S. Critchley, A.E. Siokou, R.M. Nix, PCCP 2 (2000) 4758. 